\title{
Endoscopic band ligation to create an omental patch for closure of a colonic perforation
}

A 56-year-old woman underwent colonoscopy for colorectal cancer surveillance. At a difficult rectosigmoid turn, a $1.5-\mathrm{cm}$ perforation developed, but application of two endoscopic clips (HX-610-090L, Olympus, Tokyo, Japan) failed to close the perforation because of the awkward angle ( $\bullet$ Fig. 1). A banding device (MBL-6, Wilson-Cook, Winston-Salem, North Carolina, USA) loaded on a gastroscope was then used to suck the nearby omentum to complete closure of the perforation, aided by one of the clips serving as a landmark to pinpoint the location of the perforation ( Fig.2). Subsequently, a computed tomography (CT) scan of the whole abdomen with rectal contrast revealed pneumoperitoneum, pneumoretroperitoneum, pneumomediastinum, and right pneumothorax, and confirmed absence of contrast leakage ( Fig.3). The patient was admitted and the pneumothorax was successfully treated with conservative measures, that is, the patient had no oral intake for 1 week and was given broad-spectrum antibiotics. After another 2 days, she was able to tolerate a step-up diet and was discharged. At the 1-month follow-up she had no complaints and reported normal bowel movement.

The rectosigmoid colon is vulnerable to perforation because of its angulation [1, 2]. Perforation at the rectosigmoid junction can lead to pneumoperitoneum as well as pneumoretroperitoneum because the junction is located within both the retroperitoneal and the intraperitoneal spaces. A pneumothorax may occur when air dissects through the mediastinal pleura into the pleural space [3]. The success rate of clipping for closure of a colonic perforation is about $42 \%-82 \%[4,5]$. For successful endoscopic clipping the perforation should be less than $10 \mathrm{~mm}$ in size, as larger sizes carry a significant risk of unfavorable outcome [5], and there needs to be enough space available for passing the scope under direct visualization $[4,5]$. In our patient clipping was unsuccessful as the perforation was more than $1 \mathrm{~cm}$ in size and located at the angulated part of the rectosigmoid colon.

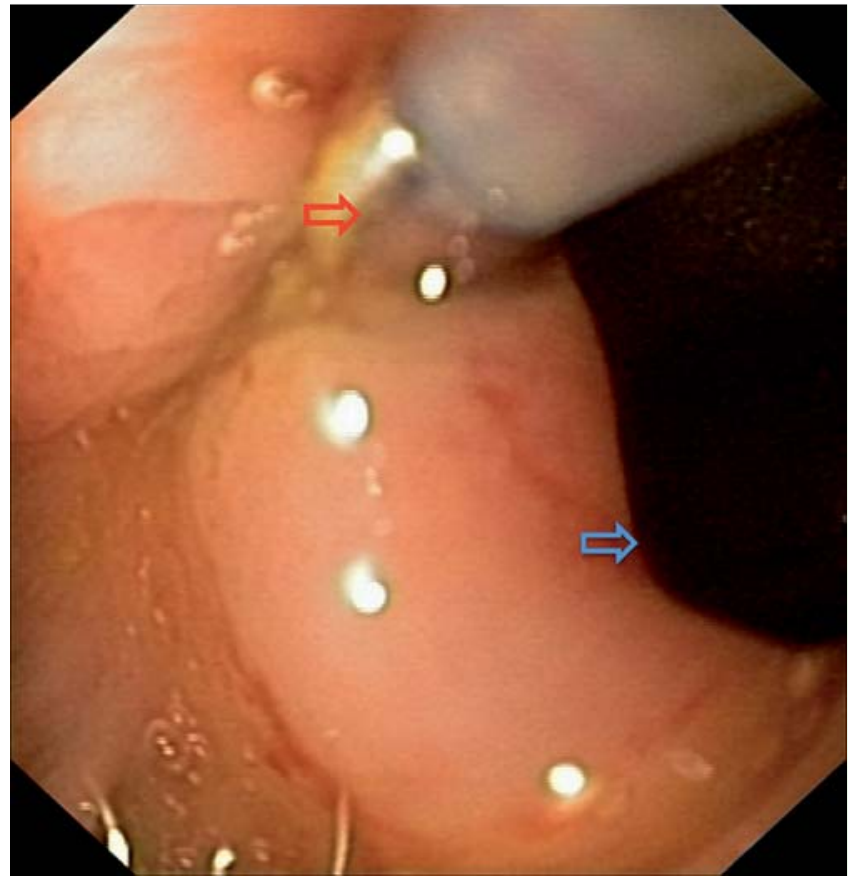

Fig. 1 Endoscopic view of the perforation (blue arrow) following a failed attempt at clipping in a 56-year-old woman undergoing colonoscopy for colorectal cancer surveillance. A clip is seen at one corner of the hole (red arrow).

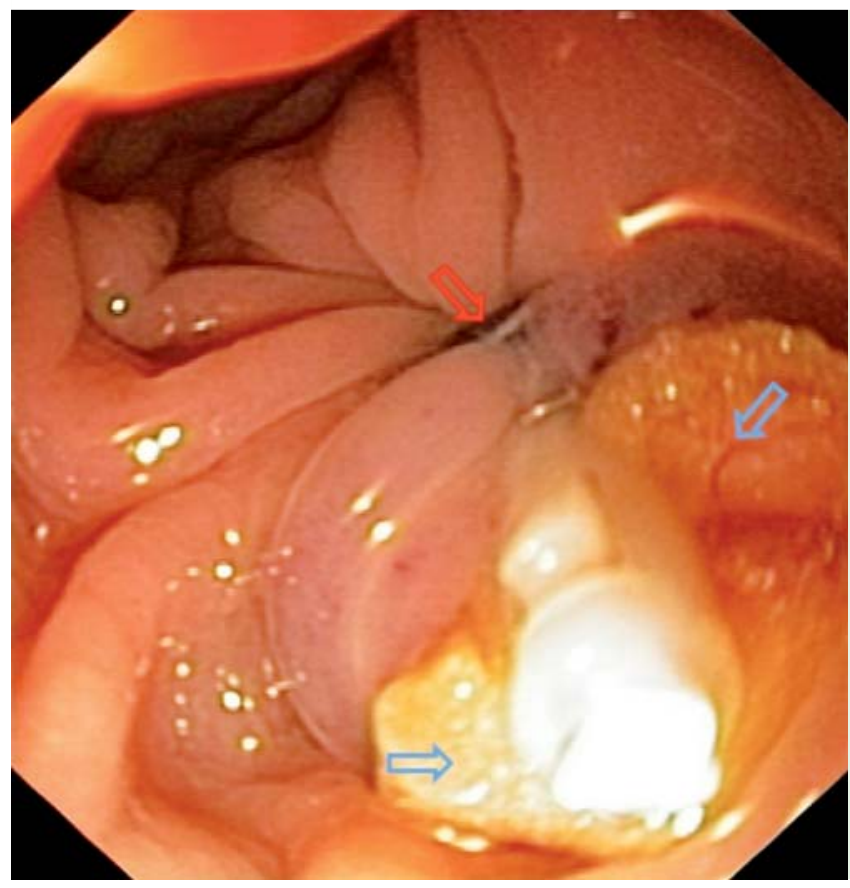

Fig. 2 Endoscopic view of successful closure of the colonic perforation by banding ligation. A black rubber band (red arrow) was used and an omental patch (blue arrows) was created.

Fortunately, we were able to use one of the previously deployed clips as a guide and suck the nearby omentum to create an omental patch endoscopically. 

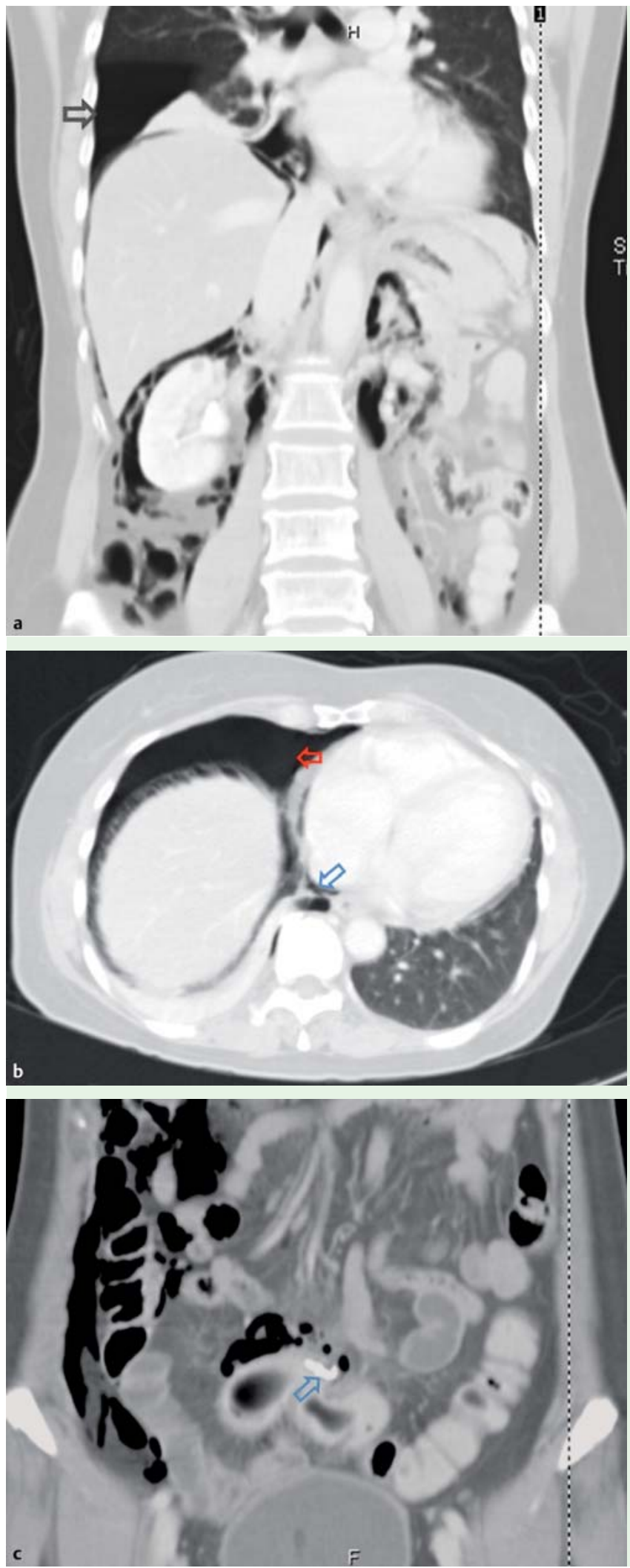

Fig. 3 Computed tomography (CT) scans showing: a pneumoperitoneum, pneumoretroperitoneum, and right pneumothorax (gray arrow); and $\mathbf{b}$ pneumomediastinum (blue arrow) and right pneumothorax (red arrow). c The CT scan with rectal contrast confirmed the absence of contrast leakage at the site of perforation, using the clip as a landmark (blue arrow).

\section{P. Angsuwatcharakon ${ }^{1}$, P. Thienchana- chaiya ${ }^{1}$, L. Pantongrag-Brown ${ }^{2}$, R. Rerknimitr ${ }^{1}$}

1 Division of Gastroenterology, Department of Medicine, Faculty of Medicine, Chulalongkorn University, Bangkok, Thailand

${ }^{2}$ Advanced Diagnostic Imaging and Image-Guided Minimal Invasive Therapy Center (AIMC), Sirikit Medical Center, Ramathibodi Hospital, Bangkok, Thailand

\section{References}

1 Khashab MA, Pickhardt PJ, Kim DH et al. Colorectal anatomy in adults at computed tomography colonography: normal distribution and the effect of age, sex, and body mass index. Endoscopy 2009; 41: 674-678

2 Hanson ME, Pickhardt PJ, Kim DH et al. Anatomic factors predictive of incomplete colonoscopy based on findings at CT colonography. AJR Am J Roentgenol 2007; 189: $774-$ 779

3 Maunder RJ, Pierson DJ, Hudson LD. Subcutaneous and mediastinal emphysema. Pathophysiology, diagnosis, and management. Arch Intern Med 1984; 144: 1447-1453

4 Jovanovic I, Zimmermann L, Fry LC et al. Feasibility of endoscopic closure of an iatrogenic colon perforation occurring during colonoscopy. Gastrointest Endosc 2011; 73: $550-555$

5 Cho SB, Lee WS, Joo YE et al. Therapeutic options for iatrogenic colon perforation: feasibility of endoscopic clip closure and predictors of the need for early surgery. Surg Endosc 23. 09. 2011 [Epub ahead of print]

Bibliography

DOI http://dx.doi.org/

10.1055/s-0031-1291642

Endoscopy 2012; 44: E90-E91

(c) Georg Thieme Verlag KG

Stuttgart · New York

ISSN 0013-726X

Corresponding author

\section{R. Rerknimitr}

Division of Gastroenterology

Department of Internal Medicine

Faculty of Medicine

Chulalongkorn University

Bangkok 10310

Thailand

Fax: +66-2-2527839

ERCP@live.com 